\title{
Genetic homogeneity in a Pontocaspian crested newt species (Triturus karelinii) suggests recent isolation of its three allopatric range sections
}

\author{
Ben Wielstra ${ }^{1,2, *}$, Jan W. Arntzen ${ }^{2}$
}

\begin{abstract}
The integration of multilocus datasets and species distribution modelling in phylogeography allows for the reconstruction of more detailed historical biogeographical scenarios than based on mtDNA data alone. We here combine these approaches to investigate the range dynamics of the crested newt Triturus karelinii, an amphibian species endemic to the Pontocaspian region, whose range comprises three allopatric range sections: a Crimean, a Caucasian and a Caspian range section. In a previous mtDNA phylogeographical survey it was suggested that the Caucasian range section was colonized from the Caspian one and that the Crimean range section was subsequently colonized from the Caucasian one. Newly collected nuclear DNA data reveal little genetic differentiation between the three range sections and species distribution modelling suggests that they only recently became isolated. Taken together, our analyses agree with a recent colonization of the Crimean range section, but rather suggest long-term persistence in both the Caspian and Caucasian range sections, with extensive gene flow between the two.
\end{abstract}

Keywords: amphibia, historical biogeography, ion torrent sequencing, Pleistocene, species distribution modelling.

\section{Introduction}

Mitochondrial DNA (mtDNA) has provided a rich source of information for constructing historical biogeographical scenarios (Avise, 2000; Beheregaray, 2008). However, the mitochondrial genome represents just a single gene tree and care should be taken not to over-interpret the geographical structuring of mtDNA (Ballard and Whitlock, 2004; Edwards, 2009). Recent breakthroughs in next-generation sequencing technology now make multilocus phylogeography more cost-effective (Ekblom and Galindo, 2011; Garrick et al., 2015). With 'nextgeneration phylogeography' (Puritz et al., 2012) the plethora of mtDNA-based biogeographical hypotheses available can now be tested and finetuned (e.g. Spinks et al., 2014; Dufresnes et al., 2020).

1 - Institute of Biology Leiden, Leiden University, 2300 RA Leiden, The Netherlands

2 - Naturalis Biodiversity Center, 2300 RA Leiden, The Netherlands

*Corresponding author;

e-mail: b.m.wielstra@biology.leidenuniv.nl
MtDNA phylogeography has illuminated the impact of the Pleistocene Ice Age's climate cycles on intraspecific biodiversity, with the overarching pattern in temperate species being glacial range retraction and interglacial range expansion (Hewitt, 2000). A particularly informative development at this time scale is the integration of species distribution modelling in phylogeography (Svenning et al., 2011; Alvarado-Serrano and Knowles, 2014), facilitated by the availability of climate reconstructions for the Last Interglacial $(\sim 130 \mathrm{Ka})$, the Last Glacial Maximum $(\sim 22 \mathrm{Ka})$ and the mid-Holocene $(\sim 6 \mathrm{Ka})$ from the WorldClim database (Hijmans et al., 2005). Because niche conservation is a reasonable assumption over such shallow geological time (Peterson, 2011), projecting species distribution models based on present locality and climate data can provide good approximations of past distribution for this time frame.

The Pontocaspian region is a geologically and climatologically dynamic region (Krijgsman et al., 2019). Phylogeographic studies focusing on a single or a few markers (mainly 
mtDNA) have revealed the importance of the region as a glacial refugium and a source for postglacial recolonization of temperate Eurasia (Fritz et al., 2009; Gvozdik et al., 2010; Recuero et al., 2012; van Riemsdijk et al., 2017; Ali et al., 2019). We here combine multilocus data and species distribution modelling to test a complex mtDNA-based biogeographical scenario proposed in a newt endemic to the Pontocaspian region.

The distribution of the crested newt Triturus karelinii comprises three allopatric range sections, distributed 1) in the lowland between the Elburz mountain range and the Caspian sea, 2) in the Caucasus mountains, and 3) on the Crimean Peninsula (Wielstra et al., 2014b). These range sections are hereafter referred to as 'Caspian', 'Caucasian' and 'Crimean' (fig. 1). A previous mtDNA phylogeography revealed considerable intraspecific genetic structuring of Pleistocene origin (i.e. $<2.58 \mathrm{Ma}$ ) and suggested a biogeographical scenario in which $T$. karelinii filled in its current range by a northwards stepping stone colonization pattern, colonizing the Caucasian range section from the
Caspian range section relatively long ago and recently the Crimean range section from the Caucasian range section (Wielstra et al., 2010). Yet, nuclear markers reveal surprisingly low intraspecific diversity in $T$. karelinii compared to the six other crested newt species (Wielstra et al., 2019).

We here use next-generation phylogeography in combination with species distribution modelling to investigate the colonization history of T. karelinii. With the mtDNA-based predictions in mind we address the following two questions:

1) Does Bayesian clustering suggest a hierarchical nested pattern, with the Crimean range section nested in the Caucasian range section, and the Crimean + Caucasian range section nested in the Caspian range section?;

2) Does species distribution modelling suggest recent (i.e. from the Last Interglacial onwards) opportunity for gene flow between the Crimean and Caucasian range sections, but limited connectivity between the Caucasian and Caspian range sections?

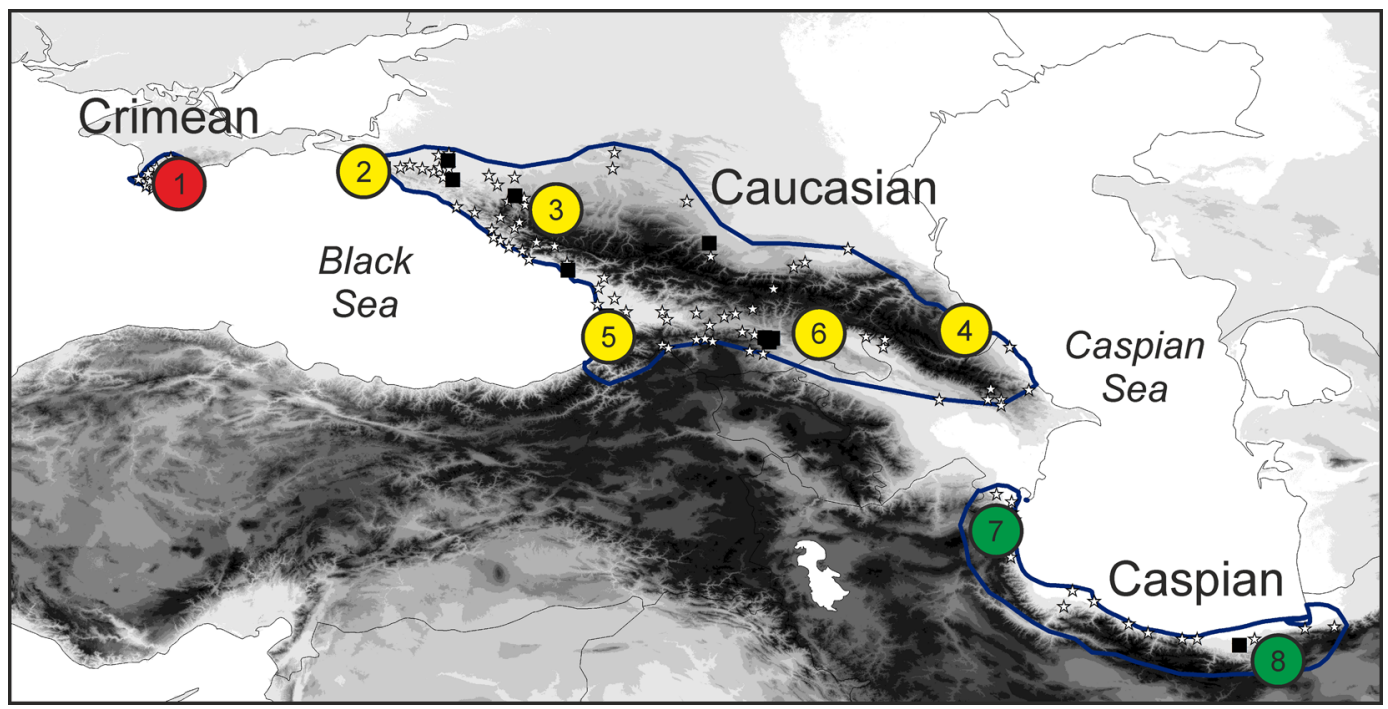

Figure 1. Sampling scheme for Triturus karelinii. Numbered localities were sequenced for nuclear DNA and correspond to table 1. The black squares reflect additional localities for which mtDNA has been sequenced and the white stars reflect localities that were on top of that used to create the species distribution model. Grey background shading reflects elevation with darker colours reflecting higher elevation. 


\section{Materials and methods}

\section{Re-analysis of mtDNA}

Sequence data for a mtDNA marker (ND4) for 106 individuals were taken from Wielstra et al. (2013) (supplementary table S1). A Median Joining network (Bandelt et al., 1999) was created using Network 4.6.11 (www.fluxusengineering.com). We constructed a phylogeny with MrBayes 3.1.2 (Ronquist and Huelsenbeck, 2003), employing two, four-chain, twenty-million-generation runs, with a sampling frequency of 0.001 and a heating parameter of 0.2. In the outgroup we included all other Triturus species and the sister genus Calotriton (Wielstra et al., 2010). The $\mathrm{GTR}+\mathrm{G}+\mathrm{I}$ model of sequence evolution was chosen as most appropriate under the Akaike Information Criterion in jModeltest 2.1.7 (Darriba et al., 2012). The first quarter of the sampled trees was discarded as burn-in after analysis of the output in Tracer 1.5 (Rambaut et al., 2018) and the inference was drawn from the remaining 'forest'.

\section{Nuclear DNA Ion Torrent sequencing and analysis}

We included three individuals per population for eight populations (i.e. 24 individuals in total) for which DNAs were available from Wielstra et al. (2013) (fig. 1, table 1). We sequenced 50 nuclear markers (for two additional markers sequencing was unsuccessful), using an the Ion Torrent next-generation sequencing protocol that can be applied to infer interspecific gene flow and intraspecific genetic structure in Triturus newts (Wielstra et al., 2014a). In brief, we amplified markers of c. $140 \mathrm{bp}$ in length (excluding primers), positioned in 3' untranslated regions, in five multiplex PCRs. We pooled the multiplexes for each individual and ligated unique tags to be able to recognize the product belonging to each individual. We sequenced the amplicons on the Ion Torrent next-generation sequencing platform and processed the output with a bioinformatics pipeline that filters out poor quality reads, identifies alleles and converts data to a format directly usable for population genetic analysis (Wielstra et al., 2014a). We obtained 852463 reads. Mean coverage was 683 (range 0 -11 118) reads per marker-individual combination and
93.7\% of marker-individual combinations were considered successful (meaning they had at least 20 reads available).

To explore population structure within T. karelinii we conducted non-spatial Bayesian clustering analysis with Structure 2.3.3 (Pritchard et al., 2000) and spatially explicit Bayesian clustering analysis with BAPS 6 (Corander et al., 2008). In these programs we determined the optimal number of gene pools $k$ over a range of 1-8 (the upper limit defined by the total number of populations included), using ten replicates per $k$ value. In Structure we used the admixture model in combination with the correlated allele frequency model, with 100000 iterations after 50000 iterations of burn-in. CLUMPAK (Kopelman et al., 2015) was used to summarize the replicates per $k$ value. In BAPS we conducted 'spatial clustering', meaning that we incorporated the geographical origin of individuals, and tested for admixture between gene pools. For Structure we used CLUMPAK to determine the optimum $k$ value according to the $\Delta k$ criterion (Evanno et al., 2005) and to identify the $k$ value for which $\operatorname{Pr}(K=k)$ is highest (see section 5.1 in the Structure manual). Because the $\Delta k$ criterion tends to underestimate genetic structure we also used Structure to analyse successively smaller clusters of individuals at $k=2$ (as in e.g. Gowen et al., 2014; we hereafter refer to this analysis as 'hierarchical Structure') until Structure did not detect any remaining nested clusters (here defined as support values for all included individuals for allocation to a cluster dropping below 0.9). We did not test for additional clusters within a single population. BAPS determines the optimum $k$ value internally. The output of the different programs under the chosen $k$ values was visualized with DISTRUCT (Rosenberg, 2004).

Population genetic differentiation was further analysed by principal component analysis (PCA) with Adegenet (Jombart and Ahmed, 2011). Pairwise $F_{\text {st }}$ distances between populations were calculated with GenePop (Rousset, 2008) and we used FSTAT (Goudet, 1995) to determine gene diversity and the number of alleles present for each population and geographic region.

Table 1. Details on Triturus karelinii populations for which nuclear DNA was sequenced. Population numbers correspond to fig. 1.

\begin{tabular}{|c|c|c|c|c|c|c|c|c|}
\hline Number & Locality & Latitude & Longitude & Group & $\begin{array}{l}\text { Average } \\
\text { gene } \\
\text { diversity }\end{array}$ & & $\begin{array}{l}\text { Average } \\
\text { number } \\
\text { of alleles }\end{array}$ & \\
\hline 1 & Ukraine: Nikita & 44.538 & 34.243 & Crimean & 0.068 & 0.068 & 1.118 & 1.118 \\
\hline 2 & Russia: Cape Malyi Utrish & 44.716 & 37.467 & Caucasian & 0.125 & \multirow{5}{*}{0.119} & 1.212 & \multirow{5}{*}{1.558} \\
\hline 3 & Russia: Psebay & 44.071 & 40.847 & Caucasian & 0.083 & & 1.135 & \\
\hline 4 & Russia: Ersi & 41.983 & 47.983 & Caucasian & 0.045 & & 1.058 & \\
\hline 5 & Georgia: Kobuleti & 41.822 & 41.814 & Caucasian & 0.100 & & 1.212 & \\
\hline 6 & Georgia: Telavi & 41.903 & 45.475 & Caucasian & 0.032 & & 1.019 & \\
\hline 7 & Azerbaijan: Avyarud & 38.500 & 48.600 & Caspian & 0.043 & \multirow[b]{2}{*}{0.077} & 1.080 & \multirow[b]{2}{*}{1.212} \\
\hline 8 & Iran: Alandan & 36.233 & 53.467 & Caspian & 0.036 & & 1.038 & \\
\hline
\end{tabular}




\section{Species distribution modelling}

Species distribution modelling was conducted with Maxent 3.3.3k (Phillips et al., 2006). To facilitate model extrapolation we restricted the feature type to hinge features as this produces a smoother model fit that emphasizes trends rather than idiosyncrasies of the data (Elith et al., 2010). We used the database of $148 T$. karelinii localities taken from Wielstra et al. (2014b) and the bioclimatic variables available at a 2.5 arcminute resolution (c. $5 \times 5 \mathrm{~km}$ ) from the WorldClim database version 1.4 (Hijmans et al., 2005). Following VanDerWal et al. (2009) we restricted the area from which pseudo-absence data were drawn to a $200 \mathrm{~km}$ buffer zone around known Triturus localities (see Wielstra et al., 2013 for details). Based on the recommendations of Guisan and Thuiller (2005) and Peterson (2011), we used a subset of layers deemed biologically meaningful and showing a Pearson's correlation of $\mathrm{r}<0.7$ : bio10 $=$ mean temperature of warmest quarter, bio11 = mean temperature of coldest quarter, bio $15=$ precipitation seasonality, bio $16=$ precipitation of wettest quarter, and bio17 = precipitation of driest quarter. For hindcasting we used bioclimatic variables, available from WorldClim, for the Last Interglacial ( $\sim 130 \mathrm{Ka}$ ) (OttoBliesner et al., 2006), the Last Glacial Maximum ( $22 \mathrm{Ka})$ and the mid-Holocene $(\sim 6 \mathrm{Ka})$. For the latter two time periods we used data derived from two global climate models:
CCSM4 (Brady et al., 2013) and MIROC-ESM (Sueyoshi et al., 2013). To determine whether our species distribution model performs better than random expectation, we tested its AUC value against a null model based on 99 models for random localities (Raes and ter Steege, 2007). Random point data were created with ENMTools 1.3 (Warren et al., 2010).

\section{Results}

The mtDNA phylogeny and haplotype network show that the highest divergence among haplotypes is found in the Caspian range section of T. karelinii (fig. 2). The Crimean haplotype is closely related to the haplotypes found in the Caucasian range section. Haplotypes from these two range sections form a significantly supported monophyletic group (posterior probability $=1.00$ ). This group is suggested to be nested within a paraphyletic group of Caspian

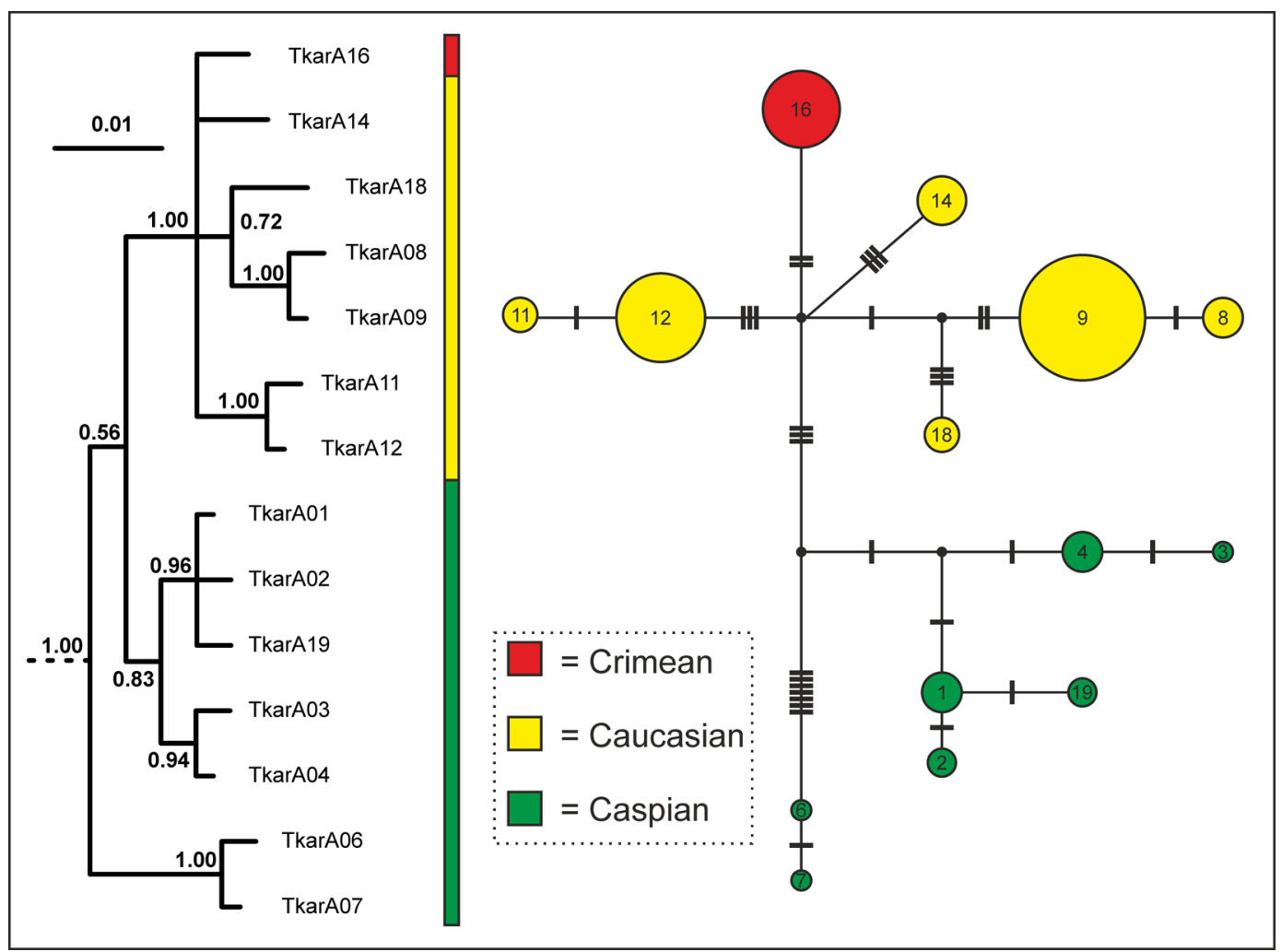

Figure 2. Phylogeny (left) and haplotype network for Triturus karelinii mtDNA. Haplotype codes (the prefix 'TkarA' has been excluded in the haplotype network) correspond to supplementary table S1. Colours reflect the three regions where haplotypes originate from. Values at nodes are posterior probability values $(<0.5$ not shown). The outgroup is not shown. 

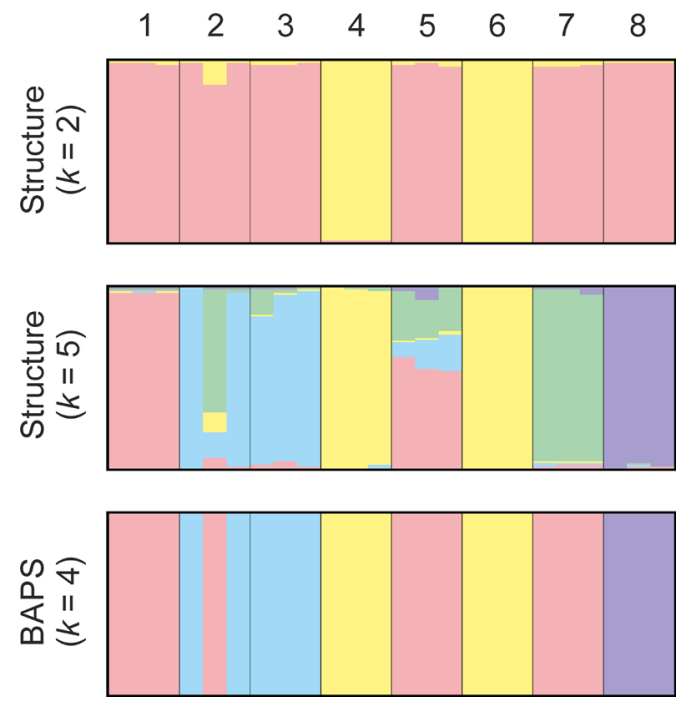

Figure 3. DISTRUCT plots showing allocation of Triturus karelinii individuals to gene pools $(k)$ based on the different Bayesian clustering programs (noted on the left with the preferred $k$ value). See the main text for details. Population numbers (noted at the top) correspond to fig. 1 and table 1 .

haplotypes, although support for this relationship is not significant.

For the nuclear DNA dataset, the Bayesian clustering programs provided different results regarding the optimal $k$. For Structure the $\Delta k$ criterion suggested $k=2$ whereas $k=5$ had the highest $\operatorname{Pr}(K=k)$. BAPS suggested $k=4$ as the most probable number of gene pools. Bayesian clustering results are summarized in Fig. 3 and admixture values for each individual based on the different analyses are in supplementary table S2. The only consistent finding is that the two eastern populations from the Caucasian range (populations 4 and 6) cluster together. With Structure under $k=2$ this is the only sub-structuring suggested. The only subsequent step in the hierarchical Structure analysis that results in a highly supported clustering splits the Iran population (population 8) from populations 1, 2, 3, 5 and 7, but the Crimean and west Georgian populations and particularly the Azerbaijan population also show affinity with this Iranian cluster (results in supplementary table S2 only). Structure under $k=5$ and BAPS under $k=4$ recognize the Iranian population

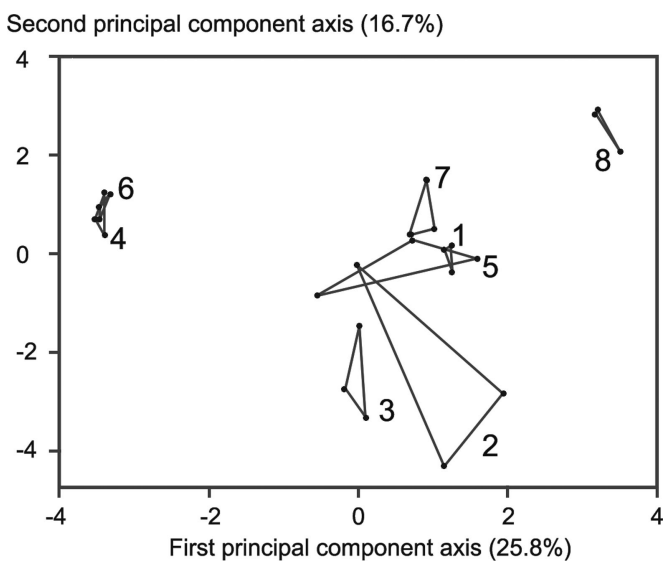

Figure 4. Results of a principal component analysis of nuclear genetic data for Triturus karelinii. Population numbers correspond to fig. 1 and table 1 .

(population 8) as a distinct cluster. The Russian populations 2 and 3 are mostly allocated to a distinct cluster as well in both analyses. Finally, Structure under $k=5$ recognizes the Azerbaijan cluster (population 7) as a distinct cluster to which several of the Caucasian clusters have affinity.

The PCA (fig. 4) suggests the two eastern populations from the Caucasian range (populations 4 and 6) and the Iran population (population 8) are both relatively diverged from the remaining populations, which cover all three range sections (populations 1-3, 5 and 7). This is in agreement with the pairwise $F_{\text {st }}$ matrix (supplementary table S3). Two measures of diversity for populations/regions, average gene diversity and the number of alleles, do not point to the Caspian population/region as being particularly genetically diverse, compared to the other populations/regions (table 1, supplementary table S4). In fact, the average gene diversity and number of alleles is highest in the Caucasian populations.

The species distribution model (fig. 5) agrees with distribution records (Wielstra et al., 2014b) that at the present the Caspian and Caucasian range sections are separated by unsuitable terrain in eastern Azerbaijan. The Crimean range section is predicted to be poorly suitable. In contrast, during the mid-Holocene and during the 


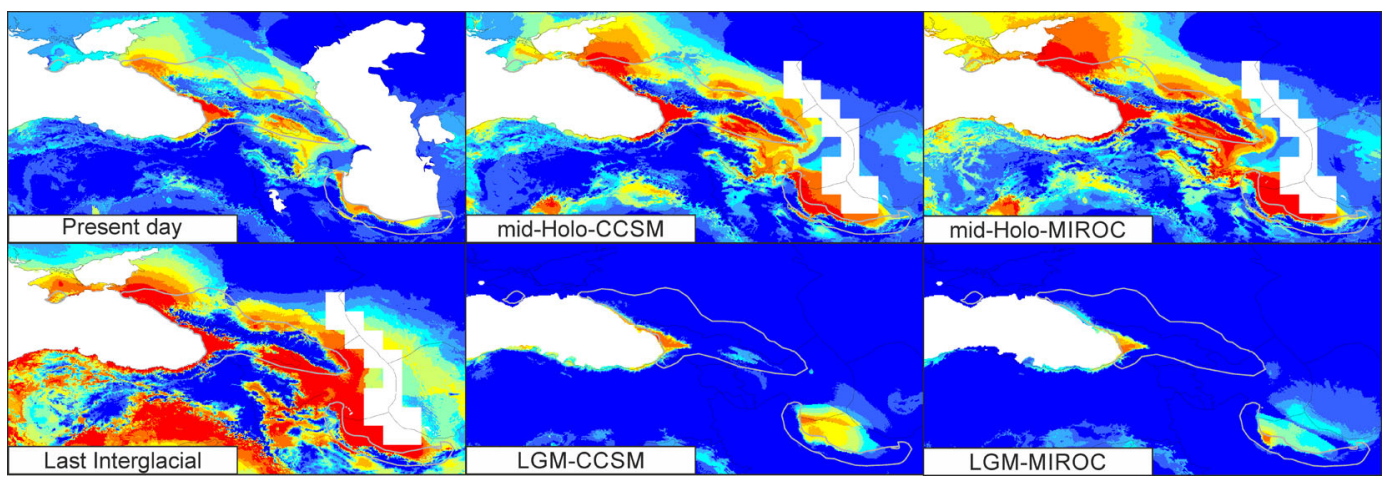

Figure 5. Species distribution model for Triturus karelinii projected on climate layers for the present, the mid-Holocene (mid-Holo, $\sim 6 \mathrm{Ka}$ ), the Last Glacial Maximum (LGM, $\sim 22 \mathrm{Ka}$ ) and the Last Interglacial $(\sim 130 \mathrm{Ka})$. For the mid-Holocene and the Last Glacial Maximum projections on data layers based on the CCSM4 (CCSM) and MIROC-ESM (MIROC) model are shown. Warmer colours reflect a higher predicted suitability.

Last Interglacial, all range sections are predicted to be suitable and furthermore connected by suitable terrain. During the Last Glacial Maximum, the availability of suitable habitat was much reduced. The area north of the Elburz Mountains and south of Caspian Sea is suggested to have retained climate conditions suitable for T. karelinii. Another area suggested to have been highly favourable is the Colchis: the area on the eastern shore of the Black Sea, extending inland between the Greater and Lesser Caucasus range. The Crimean range section was unsuitable. In the Caucasian region suitable conditions occurred in western Georgia and to a lesser extent in eastern Georgia (the latter only according to the CCSM4 climate model). Between western and eastern Georgia, between our populations 5 and 6 , a barrier of unsuitable conditions is apparent for all time frames, albeit of variable width through time.

\section{Discussion}

The crested newt $T$. karelinii is endemic to the Pontocaspian region and is distributed in three allopatric range sections (fig. 1). Re-analysis of mtDNA (fig. 2) underlines that the Crimean haplotype is closely related to, and nested within, the haplotype group occurring in the
Caucasian range section. The Caspian haplotypes are suggested to constitute a paraphyletic grouping in which the Caucasian/Crimean assemblage is nested. Combining the results from the nuclear DNA phylogeography and species distribution modelling helps us to improve the biogeographical scenario for $T$. karelinii based on mtDNA.

Bayesian structuring analysis and a PCA based on nuclear DNA do not recover the three range sections as distinct populations (figs. 3 and 4; see supplementary table S3 for pairwise $F_{\text {st }}$ distances). The only consistently retrieved grouping reveals sub-structuring within the Caucasus range section. The species distribution model suggests a pattern of repeated isolation and reconnection of the three range sections of T. karelinii (fig. 5). However, this allopatry appears to be recent: during interglacials the three range sections were connected by suitable terrain. Glacial refugia are predicted to have been present in the Caspian and Caucasian range sections, but not the Crimean range section. These results partially agree and partially disagree with our mtDNA-based predictions, as we discuss below.

All three approaches, mtDNA, nuclear DNA and species distribution modelling, agree with a scenario in which the Crimean range section was colonized after the Last Glacial Maximum, from the Caucasian range section. From 
both the mtDNA and nuclear DNA perspective, T. karelinii from the Crimean range section is closely related to T. karelinii from the Caucasian range section and shows little genetic divergence. The species distribution model predicts that at the mid-Holocene $(\sim 6 \mathrm{Ka})$ the two range sections were connected by suitable habitat. The current low suitability of the Crimean range section itself, predicted by species distribution modelling, suggests $T$. karelinii might be 'on its way out' from this range section.

The mtDNA-based hypothesis that the Caucasian (and Crimean) populations were founded from the Caspian range section is not supported. Rather than T. karelinii from the Caucasian range section being nested within $T$. karelinii from the Caspian range section, we find that most of the genetic diversity in T. karelinii resides in the Caucasian range section. The species distribution model suggests that both the Caucasian and the Caspian range sections acted as glacial refugia for T. karelinii. For other Pontocaspian taxa the region along the southern Caspian Sea coast, north of the Elburz mountains and/or the Colchis in western Caucasia have been predicted as glacial refugia as well (Leroy and Arpe, 2007; Tarkhnishvili et al., 2012; Dufresnes et al., 2016; van Riemsdijk et al., 2017; Parvizi et al., 2019).

We suggest that the absence of clear genetic structure in the nuclear genome of $T$. karelinii, despite long-term inhabitance of the currently geographically isolated Crimean, Caucasian and Caspian range sections, reflects interglacial homogenization (Garrick et al., 2019), reverting the built up of genetic variation in isolated glacial refugia (Hewitt, 2011). This study illustrates how multi-marker (nextgeneration) phylogeography and species distribution modelling can be used to improve biogeographical history initially inferred from mtDNA alone.

Acknowledgements. We thank our many colleagues who provided samples over the years.
Supplementary material. Supplementary material is available online at:

https://doi.org/10.6084/m9.figshare.13348223

\section{References}

Ali, T., Muñoz-Fuentes, V., Buch, A.-K., Çelik, A., Dutbayev, A., Gabrielyan, I., Glynou, K., Kachour, L., Khaliq, I., Kitner, M., Nigrelli, L., Ploch, S., Runge, F., Solovyeva, I., Schmuker, A., Vakhrusheva, L., Xia, X., Maciá-Vicente, J.G., Nowak, C., Thines, M. (2019): Out of Transcaucasia: origin of western and central Palearctic populations of Microthlaspi perfoliatum. Flora 253: 127-141.

Alvarado-Serrano, D.F., Knowles, L.L. (2014): Ecological niche models in phylogeographic studies: applications, advances, and precautions. Mol. Ecol. Resour. 14: 233248.

Avise, J.C. (2000): Phylogeography: the History and Formation of Species. Harvard University Press, Cambridge, Massachusetts.

Ballard, J.W.O., Whitlock, M.C. (2004): The incomplete natural history of mitochondria. Mol. Ecol. 13: 729-744.

Bandelt, H.J., Forster, P., Röhl, A. (1999): Median-joining networks for inferring intraspecific phylogenies. Mol. Biol. Evol. 16: 37-48.

Beheregaray, L.B. (2008): Twenty years of phylogeography: the state of the field and the challenges for the Southern Hemisphere. Mol. Ecol. 17: 3754-3774.

Brady, E.C., Otto-Bliesner, B.L., Kay, J.E., Rosenbloom, N. (2013): Sensitivity to glacial forcing in the CCSM4. J. Climate 26: 1901-1925.

Corander, J., Sirén, J., Arjas, E. (2008): Bayesian spatial modeling of genetic population structure. Computation. Stat. 23: 111-129.

Darriba, D., Taboada, G.L., Doallo, R., Posada, D. (2012): jModelTest 2: more models, new heuristics and parallel computing. Nat. Meth. 9: 772.

Dufresnes, C., Litvinchuk, S.N., Leuenberger, J., Ghali, K., Zinenko, O., Stöck, M., Perrin, N. (2016): Evolutionary melting pots: a biodiversity hotspot shaped by ring diversifications around the Black Sea in the Eastern tree frog (Hyla orientalis). Mol. Ecol. 25: 4285-4300.

Dufresnes, C., Nicieza, A.G., Litvinchuk, S.N., Rodrigues, N., Jeffries, D.L., Vences, M., Perrin, N., MartínezSolano, I. (2020): Are glacial refugia hotspots of speciation and cytonuclear discordances? Answers from the genomic phylogeography of Spanish common frogs. Mol. Ecol. 29: 986-1000.

Edwards, S.V. (2009): Is a new and general theory of molecular systematics emerging? Evolution 63: 1-19.

Ekblom, R., Galindo, J. (2011): Applications of next generation sequencing in molecular ecology of non-model organisms. Heredity 107: 1-15.

Elith, J., Kearney, M., Phillips, S. (2010): The art of modelling range-shifting species. Methods Ecol. Evol. 1: 330-342. 
Evanno, G., Regnaut, S., Goudet, J. (2005): Detecting the number of clusters of individuals using the software STRUCTURE: a simulation study. Mol. Ecol. 14: 26112620.

Fritz, U., Ayaz, D., Hundsdörfer, A.K., Kotenko, T., Guicking, D., Wink, M., Tok, C.V., Çiçek, K., Buschbom, J. (2009): Mitochondrial diversity of European pond turtles (Emys orbicularis) in Anatolia and the PontoCaspian region: multiple old refuges, hotspot of extant diversification and critically endangered endemics. Org. Divers. Evol. 9: 100-114.

Garrick, R.C., Bonatelli, I.A.S., Hyseni, C., Morales, A., Pelletier, T.A., Perez, M.F., Rice, E., Satler, J.D., Symula, R.E., Thomé, M.T.C., Carstens, B.C. (2015): The evolution of phylogeographic data sets. Mol. Ecol. 24: 1164-1171.

Garrick, R.C., Banusiewicz, J.D., Burgess, S., Hyseni, C., Symula, R.E. (2019): Extending phylogeography to account for lineage fusion. J. Biogeogr. 46: 268-278.

Goudet, J. (1995): FSTAT (version 1.2): a computer program to calculate F-statistics. J. Hered. 86: 485-486.

Gowen, F., Maley, J., Cicero, C., Peterson, A., Faircloth, B., Warr, T., McCormack, J. (2014): Speciation in western scrub-jays, Haldane's rule, and genetic clines in secondary contact. BMC Evol. Biol. 14: 135.

Guisan, A., Thuiller, W. (2005): Predicting species distribution: offering more than simple habitat models. Ecology Letters 8: 993-1009.

Gvozdik, V., Jandzik, D., Lymberakis, P., Jablonski, D., Moravec, J. (2010): Slow worm, Anguis fragilis (Reptilia: Anguidae) as a species complex: genetic structure reveals deep divergences. Mol. Phylogenet. Evol. 55: 460-472.

Hewitt, G. (2000): The genetic legacy of the Quaternary ice ages. Nature 405: 907-913.

Hewitt, G. (2011): Quaternary phylogeography: the roots of hybrid zones. Genetica 139: 617-638.

Hijmans, R.J., Cameron, S.E., Parra, J.L., Jones, P.G., Jarvis, A. (2005): Very high resolution interpolated climate surfaces for global land areas. Int. J. Climatol. 25: 1965-1978.

Jombart, T., Ahmed, I. (2011): adegenet 1.3-1: new tools for the analysis of genome-wide SNP data. Bioinformatics 27: 3070-3071.

Kopelman, N.M., Mayzel, J., Jakobsson, M., Rosenberg, N.A., Mayrose, I. (2015): Clumpak: a program for identifying clustering modes and packaging population structure inferences across $K$. Mol. Ecol. Resour. 15: 1179-1191.

Krijgsman, W., Tesakov, A., Yanina, T., Lazarev, S., Danukalova, G., Van Baak, C.G.C., Agustí, J., Alçiçek, M.C., Aliyeva, E., Bista, D., Bruch, A., Büyükmeriç, Y., Bukhsianidze, M., Flecker, R., Frolov, P., Hoyle, T.M., Jorissen, E.L., Kirscher, U., Koriche, S.A., Kroonenberg, S.B., Lordkipanidze, D., Oms, O., Rausch, L., Singarayer, J., Stoica, M., van de Velde, S., Titov, V.V., Wesselingh, F.P. (2019): Quaternary time scales for the Pontocaspian domain: interbasinal connectivity and faunal evolution. Earth-Science Reviews 188: 1-40.
Leroy, S.A.G., Arpe, K. (2007): Glacial refugia for summergreen trees in Europe and south-west Asia as proposed by ECHAM3 time-slice atmospheric model simulations. J. Biogeogr. 34: 2115-2128.

Otto-Bliesner, B.L., Marshall, S.J., Overpeck, J.T., Miller, G.H., Hu, A., C.L.I.P. members (2006): Simulating Arctic climate warmth and icefield retreat in the last interglaciation. Science 311: 1751-1753.

Parvizi, E., Keikhosravi, A., Naderloo, R., Solhjouy-Fard, S., Sheibak, F., Schubart, C.D. (2019): Phylogeography of Potamon ibericum (Brachyura: Potamidae) identifies Quaternary glacial refugia within the Caucasus biodiversity hot spot. Ecol. Evol. 9: 4749-4759.

Peterson, A.T. (2011): Ecological niche conservatism: a time-structured review of evidence. J. Biogeogr. 38: 817827.

Phillips, S.J., Anderson, R.P., Schapire, R.E. (2006): Maximum entropy modeling of species geographic distributions. Ecol. Model. 190: 231-259.

Pritchard, J.K., Stephens, M., Donnelly, P. (2000): Inference of population structure using multilocus genotype data. Genetics 155: 945-959.

Puritz, J.B., Addison, J.A., Toonen, R.J. (2012): Nextgeneration phylogeography: a targeted approach for multilocus sequencing of non-model organisms. PLoS ONE 7: e34241.

Raes, N., ter Steege, H. (2007): A null-model for significance testing of presence-only species distribution models. Ecography 30: 727-736.

Rambaut, A., Drummond, A.J., Xie, D., Baele, G., Suchard, M.A. (2018): Posterior summarization in Bayesian phylogenetics using Tracer 1.7. Syst. Biol. 67: 901-904.

Recuero, E., Canestrelli, D., Vörös, J., Szabó, K., Poyarkov, N.A., Arntzen, J.W., Crnobrnja-Isailovic, J., Kidov, A.A., Cogălniceanu, D., Caputo, F.P., Nascetti, G., Martínez-Solano, I. (2012): Multilocus species tree analyses resolve the radiation of the widespread Bufo bufo species group (Anura, Bufonidae). Mol. Phylogenet. Evol. 62: 71-86.

Ronquist, F., Huelsenbeck, J.P. (2003): MrBayes 3: Bayesian phylogenetic inference under mixed models. Bioinformatics 19: 1572-1574.

Rosenberg, N.A. (2004): DISTRUCT: a program for the graphical display of population structure. Mol. Ecol. Notes 4: 137-138.

Rousset, F. (2008): GENEPOP'007: a complete reimplementation of the genepop software for Windows and Linux. Mol. Ecol. Resour. 8: 103-106.

Spinks, P.Q., Thomson, R.C., Shaffer, H.B. (2014): The advantages of going large: genome-wide SNPs clarify the complex population history and systematics of the threatened western pond turtle. Mol. Ecol. 23: 22282241.

Sueyoshi, T., Ohgaito, R., Yamamoto, A., Chikamoto, M.O., Hajima, T., Okajima, H., Yoshimori, M., Abe, M., O'Ishi, R., Saito, F., Watanabe, S., Kawamiya, M., AbeOuchi, A. (2013): Set-up of the PMIP3 paleoclimate experiments conducted using an Earth system model, MIROC-ESM. Geosci. Model Dev. 6: 819-836. 
Svenning, J.-C., Fløjgaard, C., Marske, K.A., NóguesBravo, D., Normand, S. (2011): Applications of species distribution modeling to paleobiology. Quaternary Sci. Rev. 30: 2930-2947.

Tarkhnishvili, D., Gavashelishvili, A., Mumladze, L. (2012): Palaeoclimatic models help to understand current distribution of Caucasian forest species. Biol. J. Linn. Soc. 105: 231-248.

van Riemsdijk, I., Arntzen, J.W., Bogaerts, S., Franzen, M., Litvinchuk, S.N., Olgun, K., Wielstra, B. (2017): The Near East as a cradle of biodiversity: a phylogeography of banded newts (genus Ommatotriton) reveals extensive inter-and intraspecific genetic differentiation. Mol. Phylogenet. Evol. 114: 73-81.

VanDerWal, J., Shoo, L.P., Graham, C., Williams, S.E. (2009): Selecting pseudo-absence data for presence-only distribution modeling: how far should you stray from what you know? Ecol. Model. 220: 589-594.

Warren, D.L., Glor, R.E., Turelli, M. (2010): ENMTools: a toolbox for comparative studies of environmental niche models. Ecography 33: 607-611.

Wielstra, B., Espregueira Themudo, G., Güclü, Ö., Olgun, K., Poyarkov, N.A., Arntzen, J.W. (2010): Cryptic crested newt diversity at the Eurasian transition: the mitochondrial DNA phylogeography of Near Eastern Triturus newts. Mol. Phylogenet. Evol. 56: 888-896.

Wielstra, B., Crnobrnja-Isailović, J., Litvinchuk, S.N., Reijnen, B.T., Skidmore, A.K., Sotiropoulis, K., Toxopeus,
A.G., Tzankov, N., Vukov, T., Arntzen, J.W. (2013): Tracing glacial refugia of Triturus newts based on mitochondrial DNA phylogeography and species distribution modeling. Front. Zool. 10: 13.

Wielstra, B., Duijm, E., Lagler, P., Lammers, Y., Meilink, W.R.M., Ziermann, J.M., Arntzen, J.W. (2014a): Parallel tagged amplicon sequencing of transcriptome-based genetic markers for Triturus newts with the Ion Torrent next-generation sequencing platform. Mol. Ecol. Resour. 14: 1080-1089.

Wielstra, B., Sillero, N., Vörös, J., Arntzen, J.W. (2014b): The distribution of the crested and marbled newt species (Amphibia: Salamandridae: Triturus) - an addition to the New Atlas of Amphibians and Reptiles of Europe. Amphib.-Reptil. 35: 376-381.

Wielstra, B., McCartney-Melstad, E., Arntzen, J.W., Butlin, R.K., Shaffer, H.B. (2019): Phylogenomics of the adaptive radiation of Triturus newts supports gradual ecological niche expansion towards an incrementally aquatic lifestyle. Mol. Phylogenet. Evol. 133: 120-127.

Submitted: September 17, 2020. Final revision received: December 7, 2020. Accepted: December 7, 2020.

Associate Editor: Ariel Rodriguez. 